\title{
BMJ Estimation of cocaine consumption Open in the community: a critical comparison of the results from three complimentary techniques
}

\author{
Malcolm J Reid, ${ }^{1}$ Katherine H Langford, ${ }^{1}$ Merete Grung, ${ }^{1}$ Hallvard Gjerde, ${ }^{2}$ \\ Ellen J Amundsen, ${ }^{3}$ Jorg Morland, ${ }^{2}$ Kevin V Thomas ${ }^{1}$
}

To cite: Reid MJ, Langford $\mathrm{KH}$, Grung M, et al. Estimation of cocaine consumption in the community: a critical comparison of the results from three complimentary techniques. BMJ Open 2012;2:e001637. doi:10.1136/bmjopen-2012001637

- Prepublication history and additional material for this paper are available online. To view these files please visit the journal online (http://dx.doi.org/10.1136/ bmjopen-2012-001637).

Received 11 June 2012 Accepted 26 September 2012

This final article is available for use under the terms of the Creative Commons Attribution Non-Commercial 2.0 Licence; see http://bmjopen.bmj.com

${ }^{1}$ Norwegian Institute for Water Research, Oslo, Norway

${ }^{2}$ Norwegian Institute of Public Health, Oslo, Norway ${ }^{3}$ Norwegian Institute for Drug and Alcohol Research, Oslo, Norway

\section{ABSTRACT}

Objectives: A range of approaches are now available to estimate the level of drug use in the community so it is desirable to critically compare results from the differing techniques. This paper presents a comparison of the results from three methods for estimating the level of cocaine use in the general population.

Design: The comparison applies to; a set of regionalscale sample survey questionnaires, a representative sample survey on drug use among drivers and an analysis of the quantity of cocaine-related metabolites in sewage.

Setting: 14438 participants provided data for the set of regional-scale sample survey questionnaires; 2341 drivers provided oral-fluid samples and untreated sewage from 570000 people was analysed for biomarkers of cocaine use. All data were collected in Oslo, Norway.

Results: $0.70(0.36-1.03) \%$ of drivers tested positive for cocaine use which suggest a prevalence that is higher than the $0.22(0.13-0.30) \%$ (per day) figure derived from regional-scale survey questionnaires, but the degree to which cocaine consumption in the driver population follows the general population is an unanswered question. Despite the comparatively lowprevalence figure the survey questionnaires did provide estimates of the volume of consumption that are comparable with the amount of cocaine-related metabolites in sewage. Per-user consumption estimates are however highlighted as a significant source of uncertainty as little or no data on the quantities consumed by individuals are available, and much of the existing data are contradictory.

Conclusions: The comparison carried out in the present study can provide an excellent means of checking the quality and accuracy of the three measurement techniques because they each approach the problem from a different viewpoint. Together the three complimentary techniques provide a wellbalanced assessment of the drug-use situation in a given community and identify areas where more research is needed.

\section{ARTICLE SUMMARY}

Article focus

- Estimation of the prevalence of cocaine use is important for: the assessment of the needs of public health; the development of appropriate drug strategies to reduce health effects and the subsequent monitoring of the effectiveness of such strategies.

- It is generally accepted that there is a lack of information with respect to the dynamics and scale of illicit drug markets, and the validity or reliability of estimates are questionable.

- This paper presents a critical comparison of the results from three different methods for estimating the level of cocaine use in the general population.

Key messages

- Only $0.70(0.36-1.03) \%$ of drivers tested positive for cocaine use compared with $0.22(0.13$ $0.30) \%$ (per day) as derived from regional-scale survey questionnaires.

- Direct comparison of prevalence estimates with the amount of drug-related metabolites in sewage is difficult because accurate data on peruser consumption estimates is lacking.

- Such a comparison as carried out here helps to identify key short falls in the respective datasets and highlights where further research is needed.

Strengths and limitations of this study

- A rigorous ecological approach to the present study would require that the comparison was based on exactly the same population, and at the same time, but the logistics of sampling and the vastly different timescales involved in each of the three techniques make this difficult.

- No similar comparisons of the three drug epidemiology techniques have been carried out before so it is difficult to relate the present findings to other study populations.

Correspondence to

Malcolm J Reid;

malcolm.reid@niva.no 


\section{INTRODUCTION}

Cocaine is the most commonly used illicit stimulant drug in Europe and consumption remains high in the USA despite a recent decline in annual prevalence. ${ }^{1}$ Use of the drug is associated with numerous health problems including cardiovascular disorders, neurological impairment and death. ${ }^{2}$ Accurate and timely information on the prevalence of cocaine use are therefore important for assessing the needs of public health, developing appropriate drug strategies to reduce health effects and in the subsequent monitoring of the effectiveness of such strategies. While official statistics indicate that cocaine use is relatively stable in Europe and may be dropping in the USA, it is generally accepted that there is a lack of information with respect to the dynamics and scale of illicit drug markets, and the validity or reliability of estimates are questionable. ${ }^{3}$ The estimation of drug use patterns in society is currently reliant on questionnairebased data collection at the population level, and among groups of drug users, together with statistics from hospital admissions, registered drug-overdose deaths, treatment services and the records from police seizures. ${ }^{4-8}$ Validation of drug-use statistics derived from individual self-reporting has previously been attempted by drawing comparisons between the self-reported use and measurements of samples taken from hair, urine and blood. ${ }^{9-13}$ This technique has shown that despite the use of an array of methods to increase the level of accuracy of self-reporting, under-reporting is still apparent. Recently, additional data on the level of drug use at the community level have also been acquired through the implementation of anonymous road-side testing studies, ${ }^{14} 15$ and also through the measurement of drug metabolites in sewage water. ${ }^{16-21}$ With a range of different approaches now available to estimate the level of community drug use it is highly desirable to critically compare the results they provide. For the first time this paper presents a critical comparison of the results from three different methods for estimating the level of cocaine use in the general population. The comparison was performed on three studies in Oslo, Norway and applies to; a combination of user group and representative population sample survey questionnaires, a representative sample survey on drug use measured in saliva among drivers, and an analysis of the quantity of drugs and drug-related metabolites in sewage.

\section{MATERIALS AND METHODS}

\section{Background-cocaine use in Norway}

Lifetime prevalence of cocaine use in the general population 15 years and over was reported as 2.7\% in 2004 and $2.5 \%$ in $2009 .^{22}$ Results from both these studies (combined) show that the prevalence of recent cocaine use (within the last year) in the total population was as low as $0.6 \%$. A separate study on young adults (21-30 years) ${ }^{23}$ reports higher rates of cocaine use in these age groups: prevalence of use within the last 6 months was $4.3 \%$ in 2002 and $4.9 \%$ in 2006. Also, lifetime prevalence of cocaine use among young people (15-20 years) in Oslo has remained very stable in the years 2003-2008.

Cocaine use in Norway is dominated by recreational intranasal use (where the term 'recreational' is defined as regular occasional/infrequent use as opposed to dependent use). Crack use has been rare. Among young adult cocaine users less than one in a hundred reported crack use and crack is seldom seized by the police/ customs. A survey among the prison population ${ }^{24}$ identified $6 \%$ of inmates report daily or almost daily use of cocaine in the 6 months leading up to imprisonment, but frequent cocaine use is lower among marginalised and injecting drug-user groups. ${ }^{25}$

\section{Methodology for the survey of drug-use among the driver population}

Data collection was performed in the greater Oslo area in cooperation with two National Mobile Police Service (MPS) districts from April 2008 to March 2009 as part of the DRUID Project. ${ }^{26}$ Drivers of motor vehicles were selected using a stratified two-stage cluster sampling procedure. In the first stage, random geographical areas and time periods of five consecutive days were selected using a table of random sampling numbers. ${ }^{27}$ All days and times of the week and all seasons of the year were covered. Roads were chosen by randomly selecting map co-ordinates, then choosing the closest roads. For each day the police selected two study sites along the chosen roads. The sites had to be suitable as checkpoints (possibility to stop a number of cars at the same time on the roadside without causing traffic congestion) and they had to be located within about 30-45 min drive from each other. For each day, the starting time for roadside sampling was also randomly selected. However, a few of the selected time periods had to be changed to comply with working time regulations for police officers.

The second stage of the sampling procedure consisted of randomly stopping drivers within the defined $2 \mathrm{~h}$ period. The police officers were instructed to stop cars at random, rather than stopping old cars, young drivers or other possible suspects of impaired driving. The number of data collection personnel at each site was related to the expected traffic density. When one of the data collection personnel were ready for a new driver, the MPS stopped the first approaching car or motorcycle and carried out their own routine controls (breath alcohol testing or driver's licence control). Afterwards the driver was asked to proceed to the study team, who requested voluntary and anonymous participation in the project. Oral and written information about the project was given to each driver. If verbal informed consent was given, a sample of oral fluid was collected and only the following data recorded: gender, age, day of the week, time interval and geographical site. It was thus impossible to trace a given sample to a specific donor or motor vehicle. In general, the sampling procedure was designed in a way that should ensure that the drivers rendering samples should give a representative picture 
of the total driver population. Saliva samples were collected using the Statsure Saliva Sampler (Saliva Diagnostic Systems, Framingham, Massachusetts, USA). The saliva collection pad was placed under the tongue until the indicator turned blue, or until 5 min has passed and transferred to a capped vial labelled with a bar code label corresponding to the bar code of the questionnaire. The sample was kept in a plastic bag at a temperature of approximately $5^{\circ} \mathrm{C}$ for a maximum of $6 \mathrm{~h}$, and then stored at $-20^{\circ} \mathrm{C}$.

Concentrations of cocaine and benzoylecgonine in oral fluid-buffer mixtures were determined by liquid chromatography-tandem mass spectrometry, ${ }^{28}$ which specifically measured the substances in question. The amount of collected oral fluid was determined by weighing the sample, and concentrations of substances in undiluted oral fluid were calculated. The cut-off thresholds in oral fluid-buffer mixture were 0.9 and $3.6 \mathrm{ng} / \mathrm{ml}$ for cocaine and benzoylecgonine, respectively. The combined prevalence of cocaine or benzoylecgonine was estimated by a weighted average, using weights adjusted for undersampling or oversampling of the data compared with overall population statistics. ${ }^{29}$ This weighting took into account the age and gender of drivers with respect to the general population, together with an appropriate weighting for the days of the week and time of the day (table 1).

\section{Methodology for the analysis of drugs and related metabolites in sewage}

Sample collection was carried out in the greater Oslo area in cooperation with the region's largest sewage treatment plant (Vestfjorden Avløpselskap). This plant processes sewage from a metropolitan and suburban population of approximately 570000 people. An Isco 6712 portable automatic sampler (Teledyne, Lincoln, NE, USA) was used to collect samples of wastewater every hour throughout the course of September 2009. The hourly samples were pooled to produce $6 \mathrm{~h}$ composites $(n=120)$ with mid-points corresponding to 2:00, 8:00, 14:00 and 20:00 for each day of the month. Deuterated internal standards were spiked at the time of collection ( $1 \mathrm{ml}$ of benzoylecgonine-d3, cocaine-d3, cocaethylene-d8, methamphetamine-d5, metoprolol acid-d5 and ceterizine-d 8 at $50 \mathrm{ng} / \mathrm{ml}$ to give a final working concentration of $50 \mathrm{ng} / \mathrm{l}$ of each standard in sewage) and samples were acid stabilised and stored at $4^{\circ} \mathrm{C}$ until analysis.

Concentrations of cocaine and benzoylecgonine in the sewage water composites were determined by liquid chromatography-tandem mass spectrometry. ${ }^{19}$ The limit of quantification for the analytes in raw sewage was $5 \mathrm{ng} / \mathrm{l}$.

The total mass of benzoylegonine passing through the sewage treatment processes in the Oslo region over the sampling period was calculated by scaling the measured sewage concentration of the metabolite $(\mathrm{ng} / \mathrm{l})$ in each of the 120 samples (each representing $6 \mathrm{~h}$ of sewage) by the total volume of sewage (L) for that $6 \mathrm{~h}$ period. The uncertainty with this estimate is associated with errors in sampling (an estimated 5\% relative SD (RSD) based on

\begin{tabular}{|c|c|c|c|}
\hline Characteristics & $\begin{array}{l}\text { Distribution } \\
\text { among } \\
\text { drivers (\%) }\end{array}$ & $\begin{array}{l}\text { Distribution } \\
\text { in the total } \\
\text { population } \\
\text { of Oslo (\%) }\end{array}$ & Weight \\
\hline \multicolumn{4}{|l|}{ Age (years) } \\
\hline $16-24$ & 9.4 & 10.6 & 1.13 \\
\hline $25-34$ & 18.1 & 20.9 & 1.15 \\
\hline $35-44$ & 24.3 & 16.2 & 0.67 \\
\hline $45-54$ & 21.4 & 12.2 & 0.57 \\
\hline $55-64$ & 16.4 & 10.2 & 0.62 \\
\hline $65+$ & 10.4 & 11.7 & 1.13 \\
\hline Total & 100.0 & 81.8 & - \\
\hline \multicolumn{4}{|l|}{ Gender } \\
\hline Female & 29.8 & 50.6 & 1.70 \\
\hline Male & 70.2 & 49.4 & 0.70 \\
\hline Total & 100.0 & 100.0 & - \\
\hline \multicolumn{4}{|l|}{$\begin{array}{l}\text { Day of the } \\
\text { week }\end{array}$} \\
\hline Mon-Thu & 48.0 & 57.1 & 1.19 \\
\hline Fri & 8.6 & 14.3 & 1.66 \\
\hline Sat & 31.0 & 14.3 & 0.46 \\
\hline Sun & 12.4 & 14.3 & 1.15 \\
\hline Total & 100.0 & 100.0 & - \\
\hline \multicolumn{4}{|l|}{ Time of day (h) } \\
\hline 00.00-05.59 & 3.4 & 25.0 & 7.35 \\
\hline $06.00-11.59$ & 30.1 & 25.0 & 0.83 \\
\hline $12.00-17.59$ & 43.0 & 25.0 & 0.58 \\
\hline $18.00-23.59$ & 23.5 & 25.0 & 1.06 \\
\hline Total & 100.0 & 100.0 & - \\
\hline
\end{tabular}

an uncertainty analysis performed by Lai $e t a l$ ), flow measurements (4.2\% RSD), chemical analysis (5\% RSD) and biotransformation of cocaine and benzoylecgonine in the sewer system which is typically less than $10 \% .3031$

Careful consideration of the urinary excretion rates of cocaine and its metabolites are then needed for backcalculation of the total mass of cocaine consumed during the sampling period. Benzoylecgonine is the primary urinary metabolite of cocaine and accounts for $30.8 \pm 7.7 \%$ of the recoverable dose of nasally insufflated cocaine in urine. ${ }^{32}$ (Note that cocaine use in Norway is dominated by intranasal administration so the pharmacokinetic parameters used in this study are focused on this route of administration.) It is therefore assumed that the total mass of benzoylecgonine in the sewage accounts for $30.8 \pm 7.7 \%$ of the total mass of cocaine consumed by the community group. As such, the measured mass-transport rate of benzoylecgonine ( $\mathrm{g} /$ week) is multiplied by a factor 3.5 to account for the $30.8 \pm 7.7 \%$ excretion rate and the molar-ratio of cocaine to benzoylecgonine to give the total mass of consumed cocaine ( $\mathrm{g} /$ week or $\mathrm{g} /$ month).

\section{Combined population and user-group survey methodology}

The population of cocaine users was divided into two groups; socially integrated individuals (experimental, 
recreational and heavy users) and marginalised individuals (light, medium or heavy users). It was assumed that the two groups could be reached by differing survey types. ${ }^{33-36}$ Data on the socially integrated users were acquired in three different population surveys, each for a different age segment. Two or three surveys were employed to increase $\mathrm{N}$ and reduce statistical uncertainty (table 2). Since cocaine use could be seen as stable and that sampling frames, mode of administration and data collection were the same for surveys in each age segment and estimates were averaged over the surveys. Data on marginalised users were collected from surveys of prison inmates and the Oslo homeless or street population attending a needle exchange. Note that the estimated number of marginalised cocaine users was reduced by $20 \%$ because of a likely overlap between the prison and the street population. ${ }^{37} 38$ Population rates were based on the general population aged 15-64 years provided by government statistics correct to 31 December 2009. ${ }^{29}$

A 'bottom up' method was used to estimate community cocaine use in Oslo. This method multiplies the number of users by the reported frequency of use and reported amount (mass) of cocaine used. ${ }^{39-42}$ Frequency was established from the surveys (table 2) while average values of amounts were based on self-report (last survey in table 2) and the existing literature (39). The amount varied with frequency of use such that the higher the frequency the higher the dose (see table 3). Also note that consumption estimates are purity adjusted. The purity of cocaine in Norway is measured in conjunction with seizures of the drug by the police and customs. Data from the period 2007-2009 show a trend of decreasing purity over time; lately $39 \%$ in 2007 compared with $25 \%$ in $2009 .{ }^{43}$ This degree of variation is consistent with data from other nations. ${ }^{44-47}$

Estimates of the prevalence of cocaine use derived from the survey among the driving population provide data on cocaine use within a short period of time (within the last $24 \mathrm{~h}$ ). The combined survey method, however, acquires data on the prevalence of consumption within the last 12 months. To be able to compare the roadside and the combined survey method, the prevalence of use on a single day was estimated based on the frequency of use. Frequency of use, measured as the number of days used in a year, yields the probability of use on a single day for each level of frequency (see table 3). This probability, multiplied by the number of users in the frequency group, yields the expected number of users on a single day. Summing up the expected number of daily users over frequency groups and dividing by the population figure yields the prevalence of users per day.

\section{RESULTS}

\section{Survey of drug use among the driver population}

Cocaine was detected in 14 of 2341 samples from the greater Oslo area, and benzoylecgonine was detected in nine samples, none were positive for benzoylecgonine only. Therefore, only the results for cocaine were used in the estimations below. A weighted average of $0.7 \%$ of the driver population was found to be positive for cocaine using the weights presented in table 1 .

The concentration of cocaine and benzoylecgonine in oral fluid depends on the dilution of oral fluid during sampling and the recovery from the sampling device. For the samples found to be positive for cocaine, the average collection volume of oral fluid was $0.74 \mathrm{ml}$, giving an average dilution of $1: 2.4$. A recovery for cocaine of $85.6 \%$ has been reported. ${ }^{48}$ Thus, the analytical cut-off corresponded to a cocaine concentration of $2.5 \mathrm{ng} / \mathrm{ml}$ in native (undiluted) oral fluid.

\section{Results of the analysis of drugs and related metabolites in sewage}

Benzoylecgonine (the urinary metabolite of cocaine) was detected in all sewage samples collected in the Oslo region. Measurements of the flow of this cocaine metabolite in sewage indicate an average load of 428 (CI 347 to 510$) \mathrm{g}$ /week). Benzoylecgonine recovered in urine accounts for $30.8 \pm 7.7 \%$ of the initial cocaine dose, so the measured mass of this metabolite in the sewage is

Table 2 Combined population and user-group survey parameters including study population, study dates and sample size

\begin{tabular}{|c|c|c|c|c|}
\hline Target population & Survey year & Type of survey & Sample size (n) & Publication \\
\hline 15-20 years, Oslo* & $\begin{array}{l}2006,2007 \text { and } \\
2008\end{array}$ & Postal & 5104 & Vedøy and Skretting, 2009 \\
\hline 21-30 years, Oslo† & 2006 and 2010 & Postal & 3468 & Lund et al, 2007 \\
\hline 31-64 years, Oslo & 2004 and 2009 & $\begin{array}{l}\text { Questionnaire } \\
\text { completed in private }\end{array}$ & 899 & Nordlund, 2010 \\
\hline $\begin{array}{l}\text { Prison inmates, Norway } \\
\text { (national, applied to Oslo)§ }\end{array}$ & 2002 & $\begin{array}{l}\text { Questionnaire } \\
\text { completed in private }\end{array}$ & 1093 & Odegard, 2008 \\
\hline Injecting drug users, Osloł & 2000-2004 & Face to face & 3829 & $\begin{array}{l}\text { Bretteville-Jensen and } \\
\text { Amundsen, } 2009\end{array}$ \\
\hline Marginalised Users, Arendalł & 2010 & Face to face & 45 & Unpublished pilot \\
\hline $\begin{array}{l}\text { Response rates: } \\
{ }^{*} 35 \% \text {. } \\
+40-50 \% \text {. } \\
\text { †Not recorded or applicable. } \\
\S 41 \% \text {. }\end{array}$ & & & & \\
\hline
\end{tabular}


Table 3 Parameters and estimates of community-cocaine consumption for combined survey method by frequency of use categories in four surveys

\section{Survey-population $15-30$ years}

Frequency of use categories (per half year)

\section{Never}

0

Mean number of usage days per half year

Probability of use on any given day (\%)‡

Proportion of users among total age-group

$95.3(94.8-95.7)$

Frequency of use among users (\%)

Average per-user consumption, mg (pure)/weekt†

\section{Survey-population 31-64 years}

Frequency of use categories (per year)

Mean number of usage-days per year $\ddagger$

Probability of use on any given day (\%) $¥$

Proportion of users among total age-group

population $(\%) \S$

Frequency of use among users (\%)ף

Average per-user consumption, mg (pure)/week††

\section{Survey-prison population}

Frequency of use categories (per half year prior to Never

incarceration)

Mean number of usage-days per yearł‡

Probability of use on any given day (\%) $\ddagger$

64 years $(\%) \S$

Frequency of use among users (\%)

Average per-user consumption, mg (pure)/week††

\section{0}

$99.9(99.7-100)$

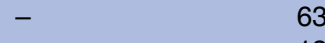

Survey-injectors/marginalised users

Frequency of use categories (per year)

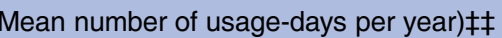

Probability of use on any given day (\%)‡

Proportion of users among total population 15-

64 years $(\%) \S$

Frequency of use among users (\%)ף

Average per-user consumption, mg (pure)/weekt†

Never

0

0

$99.9(99.6-100)$
138

\section{1-4 times}

2.5

3.0

63

6

\section{1-4 times}

2.5

0.7

0.9

50

4 or less

12

3.3

3.3
0.06

38

\section{Less than once a}

month

6

1.6

0.06

55

21

\section{$5-10$
times
7.5}

7.5

7.5

4.1
0.9

20

20
43

Monthly

12

3.3
0.5

30

42

Weekly

52

14.2

0.03

23

900
11-25 times

18

9.9

0.4

9
156

Weekly

52

14.8

0.3

15

270

Daily, almost Total/average

daily (Cl)

182.5

50.0

13

3510

Monthly

12

3.3

0.01

0.01

42

\section{5}

38
20.8

0.2

4

585

Daily, almost

daily

82.5

50.0

0.1

2106

$-$

100

100

767 (487-

1048)

Weekly

52

14.2

0.01

12
270 50+times

Total/average (CI)

100

0.2

2240

100 $154(71-237)$

Mean number of usage-days per unit time and the probability of use on a given day. Estimates of the proportion of users in the total survey population, frequency of use among users and average weekly consumption.

†Midpoint of frequency category reported in each survey, set to 116.5 for those using more than 50 times per half year.

†Defined as a usage-day or a single $24 \mathrm{~h}$ period in which cocaine is consumed. Number of usage days per user, divided by 182.6 for half-year periods and 365.25 for 1 -year periods.

$\S$ Number of users in each category divided by population figures of relevant age group.

१N Number of users in each category divided by the total number of users.

††For each category the total consumption of pure cocaine equals number of users * mean number of usage days * mean dose size * mean number of doses per day * purity. Average per user consumption per week of pure cocaine equals this amount divided by the number of users and 26 for half-year period and 52 for 1 -year period. Mean dose size and mean number of doses per day vary from $0.1 \mathrm{~g}$ and 2.5 doses in categories of lowest frequency to $0.25 \mathrm{~g}$ and eight doses in categories of highest frequency.

\#¥Midpoint of frequency category, but assuming six usage-months per year. 
equivalent to $30.8 \pm 7.7 \%$ of the total mass of cocaine consumed by the community group. The measured flow of benzoylecgonine in the Oslo sewage system is therefore indicative of a community-wide cocaine consumption rate of 1458 (CI 1158 to 1758) g/week (pure cocaine) which is equivalent to 76 (CI 60 to 91 ) $\mathrm{kg} /$ year if we assume the rate of cocaine consumption remains constant throughout the year.

\section{Combined population and user-group survey results}

Socially integrated users (aged 15-64 years) in Oslo reporting at least one instance of cocaine use in the last 12 months constituted 2.7\% (CI 2.4 to 3.1) of the total population (15-64 years) in Oslo. Proportions were highest in the age groups 20-24 years (4.0-7.6\%). Marginalised-cocaine users in Oslo constitute an additional $0.2 \%$ (CI 0.0 to 0.4 ) of the total population (15-64 years), so the proportion of the total population that admits at least one instance of cocaine use in the last 12 months is $2.9 \%$ (CI 2.6 to 3.2) in Oslo.

An estimated 0.22 (CI 0.13 to 0.30 ) \% of the population (15-64 years) use cocaine on a given day in Oslo. Approximately $80 \%$ of self-reported cocaine users (aged 15-64 years) used cocaine less than 10 times per year. The remaining proportion of the user population (20\%) have taken more cocaine more frequently and are subsequently responsible for in excess of $90 \%$ of the total daily cocaine consumption ( $\mathrm{g} /$ day). In terms of user-group population, the vast majority $(73 \%)$ of cocaine was consumed by the socially integrated population, while marginalised users (including injecting drug users and prison inmates) consumed $27 \%$ of the total.

\section{Comparison of results}

The three methods provide two distinct measures of cocaine use; the prevalence of cocaine use in terms of the proportion of the community that use the drug, and a quantitative measure (mass) of the total amount of cocaine that is consumed by the entire community.

Comparison of the prevalence estimates derived from the combined population survey $(0.22 \quad(0.13-0.30) \%$ per day) and the road-side testing $(0.70(0.36-1.03) \%)$ indicates that under-reporting and possible underrepresentation of users is apparent within the combined population surveys.
The combined population survey also provided an estimate for the total amount of cocaine that is consumed which can be directly compared with the results of sewage measurements (table 4). The estimated annual consumption rate from the combined population survey (117 (70-165) kg/year, pure cocaine) is comparable with the 76 (CI 60 to 91 ) $\mathrm{kg}$ /year figure from measurements of cocaine metabolites in sewage.

With these data it is also possible to calculate an estimated peruser consumption rate by combining the annual prevalence of cocaine use $(2.9 \%)$ with the measured annual consumption from the sewage $(76 \mathrm{~kg} /$ year $)$. Such analysis implies a peruser cocaine consumption rate of $6.4(4.6-8.5) \mathrm{g} /$ user/year (pure cocaine).

\section{DISCUSSION}

A comparison was performed on three independent methods for estimating the use of cocaine in Oslo, Norway. The comparison applies to; a combined sample survey questionnaire approach, a representative sample survey on drug use among drivers and a survey of the mass of cocaine-related metabolites in sewage. The estimated prevalence of use on a single day was higher in the survey among drivers than using the combined survey approach, while the estimated amount used (mass) in the latter was not significantly different than in the sewage approach.

The comparison identified a higher prevalence of cocaine use in the representative sample survey among drivers than in the combined sample survey questionnaire approach. Under-reporting is not unexpected in the survey questionnaires because the subject was drug use and the level of response was low, but this discrepancy may be even larger than is immediately apparent from the present study. An earlier roadside study ${ }^{49}$ found that the use of medicinal drugs was underestimated by $17-59 \%$ when using data from a survey of drivers compared with actually dispensed amounts in the studied area. For the use of cannabis the results from a roadside survey were similar to self-reported data. We therefore expect that data from a roadside survey will underestimate the use of cocaine in the adult population somewhat. In the present study marginalised drug users were included in the combined population survey but they are far less likely to own or drive motor vehicles

Table 4 Prevalence and scale of cocaine use in Oslo as determined by combined population surveys and measurements of a cocaine metabolite in sewage

\begin{tabular}{|c|c|c|c|}
\hline \multirow[b]{2}{*}{ Method } & \multirow[b]{2}{*}{ Annual Prevalence \% $(\mathrm{Cl})^{\star}$} & \multicolumn{2}{|c|}{ Cocaine Consumption (Pure) } \\
\hline & & Per-user g/year (Cl) & Total population $\mathrm{kg} / \mathrm{year}(\mathrm{Cl})$ \\
\hline Combined Population Survey (CPS) & $2.9(2.6-3.2)$ & $9.8(5.6-14.1)$ & $117(70-165)$ \\
\hline \multicolumn{4}{|l|}{ Sewage Analysis } \\
\hline Prevalence from CPS & $2.9(2.6-3.2)$ & $6.4(4.6-8.5)$ & $76(60-91)$ \\
\hline Per-user consumption from CPS & $1.9(1.0-4.0)$ & $9.8(5.6-14.1)$ & $76(60-91)$ \\
\hline
\end{tabular}


and therefore less likely to be detected in the road-side testing surveys. Second, the detection time for cocaine in oral fluid depends upon the analytical cut-off, sampling method, method of cocaine administration, dose used, acute or chronic cocaine use and other factors. In controlled studies of administration of 25-45 $\mathrm{mg}$ cocaine by intravenous injection, snorting or smoking and cocaine was detected in oral fluid for more than $12 \mathrm{~h}$ in only about $25 \%$ of the experiments. ${ }^{50}{ }^{51}$ However, cocaine may be detected in oral fluid from chronic cocaine users for up to $118 \mathrm{~h}$ after last dose in extreme cases. ${ }^{52}$ Finally, the measured prevalence $(0.7 \%)$ of cocaine or metabolites in the oral fluid of drivers is also considered a minimum because it is expected that many cocaine users refrain from driving for some hours after cocaine administration, and further, approximately $10 \%$ of drivers declined to participate in the study. It is possible that the group of drivers that refused to offer a saliva sample have a higher prevalence of recent drug consumption than that of drivers who volunteered a sample. This would give an even higher prevalence of use on a single day.

Interestingly, although the combined population survey appears to underestimate the prevalence of cocaine use, this method did result in a combined consumption estimate $(\mathrm{kg} /$ year $)$ that was not significantly different to the results of sewage analysis. This may mean that self-reported amounts of cocaine used were actually too high. Estimates of the amount of cocaine used were the weakest part of the combined population survey, however, and the frequency categories were also rather coarse. If there was a non-accounted overlap between the population survey and the surveys among marginalised users to cover the cocaine user population, this would reduce both the estimated proportion of users and the estimated amount. In addition, it is important to remember that the accuracy of the sewage estimate is strongly affected by the accuracy of the clinical pharmacokinetic data on cocaine. The present study used the pharmacokinetic parameters that apply for intranasal cocaine use because this is the most relevant for study population. This implies that a degree of back-ground information from combined population surveys with regard to the proportion of differing routes of administration are required before accurate sewage measurements are feasible. For example, the use of the intranasal pharmacokinetic parameters would not be appropriate if the study was carried out in a region with extensive crackcocaine use as the excretion patterns differ for differing routes of administration.

No similar comparisons of the three drug epidemiology techniques have been carried out before so it is difficult to relate the present findings to other study populations. It was however necessary, with the present study, to make some general assumptions with regard to the average amount of cocaine used per individual in order to adequately compare the prevalence estimates with that of the measured mass of cocaine metabolites in sewage. The combined population surveys indicated an average peruser consumption rate of $9.8 \mathrm{~g} /$ user/year (pure cocaine) which is much lower than the $30.2 \mathrm{~g} /$ user/year (in Europe) proposed by The United Nations Office on Drugs and Crime (UNODC). ${ }^{53}$ While it appears that the average per-user consumption rate in Oslo may actually be lower than in many other European regions, ${ }^{21}$ the UNODC does state that their estimate (which is based on empirical data from a small number of locations and makes significant assumptions with regard to the importance of drug availability and the effectiveness of law enforcement) is a considerable approximation as little or no data on the quantities consumed by individuals is available, and much of the existing data are contradictory. ${ }^{54}$ The results of the present study do suggest that combining accurate measurements of the total drug consumption in the population (via sewage analysis) with reliable prevalence figures acquired through rigorous survey of the population could provide improvements to the accuracy of average peruser consumption figures in the future.

The comparison carried out in the present study has provided an excellent means for checking the quality and accuracy of each the three measurement techniques because they each approach the problem from different angels. The results do however highlight the difficulties associated with performing such a comparison. A rigorous ecological approach to the present study would require that the comparison was based on exactly the same population, and at the same time, but the logistics of sampling and the vastly different timescales involved in each of the three techniques make this difficult. It is possible, for example, that the population of drivers that took part in the road-side study included individuals that were in transit and therefore from outside the region covered by the combined population survey. Similarly, results of the sewage analysis are based on a 1-month period and an assumption is made that combined cocaine use (by the total population) remains relatively constant throughout the year. These problems do however allow more precise research questions to be formulated: how can we better combine surveys to better cover all segments of the population? Does cocaine use in the population of drivers follow the same pattern as cocaine use in the general population? How can we better estimate the amounts used? How can we better estimate frequency of use? Short-falls have been identified in each of the three epidemiology techniques when used in isolation, but together the three complimentary techniques provide a well-balanced assessment of the drug-use situation in a given community with limited reliance on derived estimates.

\section{CONCLUSION}

Under-reporting is apparent in prevalence estimates provided by the combined population surveys when compared with the proportion of motor-vehicle drivers with detectable levels of cocaine or cocaine metabolites in oral fluid, but an unanswered question is whether cocaine use 
in the population of drivers follows the same pattern as cocaine use in the general population. Direct measurements of sewage from a defined population provide data on the size of the cocaine market in a particular region (albeit with a degree of uncertainty). These measurements indicate that self-reported cocaine consumption may be overexaggerated and highlight the large degree of uncertainty with respect to peruser consumption estimates. Each of the three techniques has significant short falls when used in isolation, but together they deliver complimentary data which provides a well-balanced assessment of the drug-use situation in a given community and identify areas where more research is needed.

Acknowledgements This work was funded by The Research Council of Norway under the Program for Drug and Alcohol Research (RUSMIDDEL), NFR No. 185523/ V50. The collection and analysis of oral fluid samples was sponsored by the European Commission through the 6th Framework Programme funded integrated project DRUID, contract no. TREN-05-FP6TR-S07.61320-518404-DRUID, and by the Norwegian Research Council, NFR No. 189735/110. This report reflects the authors' views only. The funders are not liable for any use that may be made of the information contained herein. The funders had no influence on the conduct of the study, interpretation and analysis, and decision to publish.

Contributors JM and KVT conceived the study. MJR carried out sewage analysis and led the preparation of the manuscript. EJA collated and managed the data-sets associated with the population surveys. HG provided data for the road-side survey. All authors contributed to interpretation of the results. All authors were involved in drafting and reviewing the manuscript. MJR and EJA act as guarantors for the manuscript.

Funding This work was funded by The Research Council of Norway under the Program for Drug and Alcohol Research (RUSMIDDEL), NFR No. 185523/N50. The collection and analysis of oral fluid samples was sponsored by the European Commission through the 6th Framework Programme funded integrated project DRUID, contract no. TREN-05-FP6TR-S07.61320-518404-DRUID, and by the Norwegian Research Council, NFR No. 189735/110. This report reflects the authors' views only. The funders are not liable for any use that may be made of the information contained herein. The funders had no influence on the conduct of the study, interpretation and analysis and decision to publish.

Competing interests None.

Provenance and peer review Not commissioned; externally peer reviewed.

Data sharing statement No additional data are available.

\section{REFERENCES}

1. United Nations Office on Drugs and Crime (UNODC). World drug report. New York: UNODC, 2012.

2. European Monitoring Centre for Drugs and Drug Addiction. Cocaine and crack cocaine: a growing public health issue. Luxembourg: Office for Official Publications of the European Communities, 2007.

3. United Nations Office on Drugs and Crime (UNODC). World drug report. New York: UNODC, 2009.

4. Kroutil LA, Vorburger M, Aldworth J, et al. Estimated drug use based on direct questioning and open-ended questions: responses in the 2006 National Survey on Drug Use and Health. Int J Methods Psychiatr Res 2010;19:74-87.

5. Aldworth J, Colpe LJ, Barker PR, et al. The National Survey on Drug Use and Health Mental Health Surveillance Study: calibration study design and field procedures. Int J Methods Psychiatr Res 2010;19:36-48.

6. Substance Abuse and Mental Health Services Administration. Results from the 2008 National Survey on Drug Use and Health: National Findings. Rockville, MD: SAMHSA, 2009.

7. Johnston LD, O'Malley PM, Buchman JG, et al. Monitoring the future: national results on adolescent drug use. overview of key findings, 2008. Maryland: National Institute on Drug Abuse (NIDA) Publication No. 09-7401, 2009.
8. Kraus L, Augustin R, Frischer M, et al. Estimating prevalence of problem drug use at national level in countries of the European Union and Norway. Addiction 2003;98:471-85.

9. Basurto FZ, Montes JM, Cubos PF, et al. Validity of the self-report on drug use by university students: correspondence between self-reported use and use detected in urine. Psicothema 2009;21:213-19.

10. Harris KM, Griffin BA, McCaffrey DF, et al. Inconsistencies in self-reported drug use by adolescents in substance abuse treatment: implications for outcome and performance measurements. J Subst Abuse Treat 2008;34:347-55.

11. Harrison LD, Martin SS, Enev T, et al. Comparing Drug Testing and Self-Report of Drug Use among Youths and Young Adults in the General Population. Substance Abuse and Mental Health Services Administration. DHHS Publication No. SMA 07-4249, 2007.

12. Musshoff F, Driever A, Lachenmeier K, et al. Results of hair analyses for drugs of abuse and comparison with self-reports and urine tests. Forensic Sci Int 2006;156:118-23.

13. McNagny SE, Parker RM. High prevalence of recent cocaine use and the unreliability of patient self-report in an inner-city walk-in clinic. JAMA 1992;267:1106-8.

14. Lacey JH, Kelley-Baker T, Furr-Holden D, et al. Pilot test of new roadside survey methodology for impaired driving. Washington, DC: National Highway Traffic Safety Administration, 2007.

15. Gjerde $\mathrm{H}$. Prevalence of alcohol and drugs among Norwegian motor vehicle drivers: a roadside survey. Accid Anal Prev 2008;40:1765-2.

16. European Monitoring Centre for Drugs and Drug Addiction. Assessing illicit drugs in wastewater-potential and limitations of a new monitoring approach. Luxembourg: Office for Official Publications of the European Communities, 2008.

17. Banta-Green CJ, Field JA, Chiaia AC, et al. The spatial epidemiology of cocaine, methamphetamine and 3,4-methylenedioxymethamphetamine (MDMA) use: a demonstration using a population measure of community drug load derived from municipal wastewater. Addiction 2009;104:1874-80.

18. van Nuijs A, Castiglioni S, Tarcomnicu I, et al. Illicit drug consumption estimations derived from wastewater analysis: a critical review. Sci Total Environ 2011;409:3564-77.

19. Reid MJ, Langford KH, Mørland J, et al. Quantitative assessment of time dependent drug-use trends by the analysis of drugs and related metabolites in raw sewage. Drug Alcohol Depend 2011;119:179-86.

20. Zuccato $E$, Castiglioni $S$, Tettamanti $M$, et al. Changes in illicit drug consumption patterns in 2009 detected by wastewater analysis. Drug Alcohol Depend 2011;118:464-9.

21. Thomas KV, Bijlsma L, Castiglioni S, et al. Comparing illicit drug use in 19 European cities through sewage analysis. Sci Total Environ 2012;432:432-9.

22. Nordlund S. Drug use in the general population and specific targeted groups. In: The Drug Situation in Norway, 2010. Annual Report to the European Monitoring Centre for Drugs and Drug Addiction. Oslo: SIRUS, 2010.

23. Lund MK, Lund KE, Skretting A. Rusmiddelbruk blant unge voksne, 21-30 år: resultater fra spørreskjemaundersøkelser 1998, 2002 og 2006. (In English: substance use among young grownups, 21-30 years: results from surveys 1998, 2002 and 2006). Oslo: SIRUS, 2007.

24. Odegard E. Narkotika- og alkoholproblemer blant innsatte i norske fengsler. (In English: Drug and alcohol problems among inmates in Norwegian prisons). Nordic Studies Alcohol Drugs 2008;25:169-85.

25. Amundsen EJ, Bretteville-Jensen AL. Hard drug use in Norway. Nordisk alkohol narkotikatidskrift 2010;27:87-94.

26. Houwing S, Hagenzieker M, Mathijssen R, et al. Prevalence of alcohol and other psychoactive substances in drivers in general traffic. Part l: general results. DRUID deliverable D.2.2.3. Liedschendam: SWOV Institute for Road Safety Research, 2011.

27. Lindley DV, Miller JCP. Cambridge elementary statistical tables. Cambridge: Cambridge University Press, 1966.

28. Oiestad EL, Johansen U, Christophersen AS. Drug screening of preserved oral fluid by liquid chromatography-tandem mass spectrometry. Clin Chem 2007;53:300-9.

29. Statistics Norway. Statistical Yearbook of Norway 2009. Oslo: Statistisk sentralbyrå, 2009. http://www.ssb.no/english/yearbook/ (accessed 17 Jan 2012).

30. Lai FY, Ort C, Gartner C, et al. Refining the estimation of illicit drug consumptions from wastewater analysis: co-analysis of prescription pharmaceuticals and uncertainty assessment. Water Res 2011:45:4437-48.

31. Castiglioni S, Bijlsma L, Covaci A, et al. Evaluation of uncertainties associated with the determination of community drug use through the measurement of sewage biomarkers. Unpublished Article Currently Under Review. 
32. Khan U, Nicell JA. Refined sewer epidemiology mass balances and their application to heroin, cocaine and ecstasy. Environ Int 2011;37:1236-52.

33. Warburton H, Turnbull PJ, Hough M. Occasional and controlled heroin use: not a problem? Drug and alcohol series. York: Joesph Roundtree Foundation, 2005

34. Harrison LD. Cocaine using careers in perspective. Addict Res 1994:2:1-20.

35. Green A, Pickering H, Foster R, et al. Who uses cocaine? Social profiles of cocaine users. Addict Res 1994;2:141-54.

36. Zinberg NE. Drug, set and setting. The basis for controlled intoxicant use. New Haven: Yale University Press, 1984.

37. Ødegård E, Amundsen EJ, Kielland KB, et al. The contribution of imprisonment and release to fatal overdose among a cohort of Norwegian drug abusers. Addict Res Theory 2010;18:51-8.

38. Bretteville-Jensen AL. Økonomiske aspekter ved sprøytemisbrukernes forbruk av rusmidler. En analyse av intervjuer foretatt 1993-2004. (In English: Economic aspects of substance consumption among IDU. An analysis of data from 1993 to 2004). Oslo: SIRUS, 2005

39. Mckeganey N, Casey J, Mcgallagly J, et al. Heroin seizures and heroin use in Scotland. J Subst Use 2009;14:240-9.

40. Bretteville-Jensen AL, Amundsen EJ. Heroinbruk og heroinbeslag $i$ Norge (In English: Heroin use and heroin seizures in Norway). Oslo: SIRUS, 2009.

41. Moore TJ, Caulkins JP, Ritter A, et al. Heroin markets in Australia: current understandings and future possibilties. Fitzroy: Turning Point Alcohol and Drug Centre, 2005.

42. Bramley-Harker E. Sizing the UK market for Illicit Drugs. London: Home Office, Research, Development and Statistics Directorate, 2001.

43. The Norwegian Police Service (KRIPOS). Narkotikastatistikk (Drug statistics) 2009. Oslo: Justis- og politidepartementet, 2009. www. politi.no/kripos/statistikk/narkotika (accessed 29 May 2011).
44. Evrard I, Legleye S, Cadet-Taïrou A. Composition, purity and perceived quality of street cocaine in France. Int J Drug Policy 2010;21:399-406.

45. European Monitoring Centre for Drugs and Drug Addiction. Analysis of the drug situation in Europe: statistical bulletin 2009. 2009. http:// www.emcdda.europa.eu/drug-situation (accessed 17 Jan 2012).

46. Schifano F, Corkery J. Cocaine/crack cocaine consumption, treatment demand, seizures, related offences, prices, average purity levels and deaths in the UK (1990-2004). J Psychopharmacol 2008;22:71-9.

47. Fries A, Anthony R, Cseko A, et al. The price and purity of illicit drugs: 1981-2007. Alexandria, Virginia: Institute for Defense Analyses, 2008

48. Langel K, Engblom C, Pehrsson A, et al. Drug testing in oral fluidevaluation of sample collection devices. J Anal Toxicol 2008;32:393-401.

49. Gjerde H, Normann PT, Mørland J. Can the use of psychoactive drugs in the general adult population be estimated based on data from a roadside survey of drugs and driving? Norsk Epidemiol 2011:21:49-54.

50. Jenkins AJ, Oyler JM, Cone EJ. Comparison of heroin and cocaine concentrations in saliva with concentrations in blood and plasma. $J$ Anal Toxicol 1995; 19:359-74.

51. Cone EJ, Oyler J, Darwin WD. Cocaine disposition in saliva following intravenous, intranasal, and smoked administration. J Anal Toxicol 1997;21:465-75.

52. Jufer RA, Wstadik A, Walsh SL, et al. Elimination of cocaine and metabolites in plasma, saliva, and urine following repeated oral administration to human volunteers. J Anal Toxicol 2000;24:467-77.

53. United Nations Office on Drugs and Crime (UNODC). World drug report 2010. New York: UNODC, 2010.

54. United Nations Office on Drugs and Crime (UNODC). World drug report 2005. Lisbon: UNODC, 2005. 